\title{
Understanding Class Teaching Authority From a Feminism Perspective
}

\author{
Hu Bai-yun \\ Southwest University, \\ Chongqing, China \\ Chongqing, China
}

\author{
Ma Cheng \\ Guizhou Nomal University, \\ Guiyang, China
}

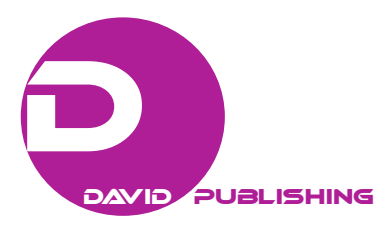

\begin{abstract}
Class teaching authority (TA) refers to teachers' authority to choose, manage, and judge the factors which are concerned in the process of teaching. Under the influence of traditional Chinese hierarchical social class and feudal ruling ideology, teachers' behavior in China generally exhibits controlling and restraining. It is the common pursuit of feminism to care for the weaker groups and to realize equality of sexes. Therefore, from the perspective of liberation, feminism endeavors to liberate those who are suppressed in education and to raise their awareness of equality, hence, promote their self-consciousness in development. Following this principle, there are three ways to achieve the feminist TA: 1. Students should be empowered to share authority with teachers; 2. A learning community should be built; and 3 . A caring relationship should be created between teachers and students.
\end{abstract}

Keywords: feminism, teaching authority (TA), liberation, empower

\section{Introduction}

The classroom authority of teachers is a special one which would make teaching go smoothly in the process of teaching. The proper wielding of authority would balance the rights between teachers and students. It could reflect the democratic degree of teaching. However, most teachers have misconceptions about teaching authority (TA) according to our investigation. They have conceived that TA meant control and restriction. Thus, their misconceptions and practice convert the classroom into a place of controlling students. Their practice could not let students play the preponderant role and inspire their initiative. Therefore, TA must be re-examined and reviewed in order to form a new conception and improve the undemocratic phenomenon of teaching.

\section{Analysis of TA in the Classroom}

During the whole process of classroom teaching, teachers wield authority all the time. The proper wielding of authority would basically guarantee the efficiency of teaching. Thus, what is TA in the classroom? How many types of TA? These are the must-be answered questions to understand TA.

\section{The Conception of TA}

The consensus of TA is the inferior conception of teachers' authority. Some scholars divided teacher's authority into several categories in accordance with different objects of imposing the authority: the authority targeting students, the authority towards courses, the authority of teaching, the authority regarding evaluation,

Hu Bai-yun, Ed.D., lecturer, School of Marxism Studies, Marxism Theory Research Center, Southwest University.

Ma Cheng (Corresponding author), M.Ed., lecturer, School of Education Science, Guizhou Nomal University.

Li Sen, Ed.D., professor, Faculty of Education, Southwest University. 
etc. (Li, 2008, p. 11). However, during the whole teaching process, teachers' activities simultaneously involved students, courses, teaching, evaluation, etc.. Therefore, TA in the classroom is a systematic adjustment in order to unfold teaching activity effectively.

Regarding the conception of TA, foreign scholars explored it in different perspectives. For instance, an American education-sociologist, Mary Haywood Metz, defined TA as a unique game relationship of control and anti-control in the teaching activity between teachers and students (Metz, 1978). Such relationship is bound by the social ethic and the pattern of education and teaching. This relationship is led by teachers in teaching activity which guides students' learning and promotes their development.

According to sociologist Christopher Hurn, TA should be transformed from the traditional hierarchical system to a progressive teaching professional dominated type (Hurn, 1985). Freire's (1990) Pedagogy of the Oppressed advocated that teachers and students possess equal power. Giroux (1986) regarded TA as a reverse-thinking relationship. To him, this relationship does not require students to accept teachers' authority. On the contrary, teachers request students to delay the trust process of TA and share TA together with students. The post-structurist Patti Lather recommended that teachers borrow and pursue the liberation interest of post-modernism practice trend (Lather, 1991). The traditional classroom TA should be discarded. New TA equal relationship would include reconstruction, participation, dialogue, pluralism, declassification, no stratum, and discarding knowledge-power centered way.

From several foreign scholars' discussions of TA, we may conclude that TA is a conception influenced by ideology of society. Based on different backgrounds of social culture and study perspectives, TA would have different interpretations. But one thing is universal of their viewpoints: An equal and jointly applicable pattern of TA is emphasized. Teachers' objective of TA itself is no longer to control and restrain, but to create an atmosphere of teacher-student equalization and democratic participation. A teacher can maximize his/her professional dominance, personal charisma, and soft management to shape unique TA in order to influence students and reach the goal of student development.

Some domestic scholars defined TA as a preponderant force of teacher in the time-space atmosphere of classroom functioning with combined factors of teaching profession, social culture, self situation, and students in order to promote student development as an essential goal (Liu, 2010). This definition of TA has its rationality because of its boundary over the function of TA, but it is not concrete and operational regarding the exercise process of TA.

From the perspective of how to use TA, we define TA as the teacher having the authority of selection, decision, management, and evolution in the teaching process of a variety of factors. It includes teachers' selection and decision regarding the content of teaching, the method, the means of teaching, as well as the management and evolution of the classroom and students. These authorities of a teacher are entrusted and endowed by the social culture, school system, and the professional level. As the subject of TA, teachers' understanding of TA and their skills of wielding authority affect the state of exercising TA in the classroom.

\section{Four Types of TA}

The methods of Metz are worth considering while we define types of TA. Metz (1978) categorized TA into four types in accordance with their sources: traditional authority, extraordinary charisma, legal authority, and professional authority. After our investigation, these types of TA have been in China.

Traditional TA. Metz regarded it as the acknowledgement of ancient none traceable origin and the 
observation of sacred customs. Teachers expect students to obey simply because they are teachers with patriarch style of traditional sanctity. This authority is endowed with the teaching profession. Teachers were highly respected. "Heaven", "earth", "emperor", "father", and "teacher" were worshiped in the shrine of every family in ancient China. It is still well-known that whoever is being a one-day teacher for students and he/she would be the "father" of the students for the rest of their lives. Nowadays, the social status of teachers is being degraded, but the favorable tradition of respecting teachers is still being preserved in China. Teaching profession itself signifies that teachers have the authority of teaching and cultivating students.

Extraordinary charisma. Metz (1978) said:

Students are aroused by the personal charisma of teachers without attachment to any regulations and system. Also, it has nothing to do with mighty stifling. More often, it comes from the teacher's humorous style, erudite, and profound mind which affect students naturally. (pp. 42-52)

This authority originates from the personal charisma and teaching style of teachers. The unique personal charisma, wit, erudite, sagacity, etc. would be an attractive force subduing students who are willing to comply and cooperate with arrangement and management of teachers.

Legal authority. Metz (1978) wrote:

Legal authority is implemented by the trust of school regulations and terms with effectiveness and objectivity. It is an authority of none personalization. Whatever conforms to regulations in the execution of duty is expected to obey. (pp. 45-52)

Teachers are managers and leaders in the organization structure formed by teachers and students. Teachers must be backed up by certain policies and regulations whenever manage students. Policies and regulations themselves have possessed certain authority. When teachers act in accordance with policies and regulations - coerced management means - they simultaneously have the executioners' authority.

Professional authority. In Metz's opinion, supposedly, teachers are learned persons with professional specialty. With their knowledge and capability, they can train students, teach them some skills, and clarify their puzzled minds. Besides, the UNESCO's (1996) “The Proposals of Teacher's Status" clearly defined the role of teachers: "Teachers should play the decisive role in the selection and revision of textbooks, the review and evaluation of textbooks and the practical application of teaching methods" (pp. 1-6). In other words, teachers have the authority to select and make decisions regarding relevant aspects of majors. In classroom teaching, teachers have the authority of professional autonomy. They can arrange concrete teaching activities to guarantee the teaching going smoothly with their professional capability under the guidance of professional theory in accordance with their understanding of teaching and students.

\section{The Reality of TA: Controlling and Restraining}

The Chinese cultural tradition for thousands of years habitually defers to authority and adjoins to others or organ of authority. Under the influence of such cultural tradition, teachers as an authority become objects students defer and adjoin to. At the same time, students following teachers are regarded as manifestation of respecting teachers and steadily strengthened. Eventually, the authority of teachers is solidified and the rights of students are weakened. When the disparity between teachers and students becomes too great, the exercise of TA inevitably leads to controlling and restraining. 


\section{Four Aspects in Control and Restriction of TA}

According to some scholars:

The essence of authority is force. In an authority structure, the subject of authority is a preponderant force over the object of authority; their relations often become order-obey relation. Generally speaking, the authority object does not have the force counterbalancing the subject of the authority. Thus, the authority object only temporarily or permanently is restrained and controlled by the subject of authority. However, if the authority structure changes (through revolution, reform, etc.), their status of subject and object may be altered. (Wu \& Li, 2011, pp. 80-85)

Therefore, the interpretation of authority as a preponderant force determined by status has certain enlightening significance regarding TA in the classroom.

Although TA is a special authority, but it has the characteristics of general authority. Teachers and students constitute the subject and object of the authority. Teachers' superiority in knowledge, experiences, and other factors dominates the control-restrain, order-obey relationship between teachers and students:

1. Teachers have the authority to evaluate and assess the effectiveness of students' learning with pre-set standers due to their authority designated by traditional culture and their mastery of knowledge beforehand. Under such circumstances, students have to accept TA passively;

2. The ensured TA gap between teachers and students endows teachers' force of controlling and restraining students;

3. TA is safeguarded by disciplines and a series of reward-punitive measures. Teachers have the authority to manage students with standardization;

4. TA can supervise, transform, and cure students. It makes teachers believe that they are disseminators or interpreters of correct, good behavior or lifestyle. Students must accept it.

In a word, traditional and legal TA is superfluous and excessive. TA of extraordinary charisma and professional are insufficient. Teachers' view of teacher-student relations is still lingered in the teacher-centered long-gone past. They have not realized the change of students' status and the necessity of exerting rights of students.

\section{The Origin of Control and Restriction in TA}

TA has formed by several jointly factors with its core of social and cultural factor of school. For thousands of years of feudal ruling, the value thinking way of social stratum and ruling logic has influenced the consciousness of people profoundly and lastingly. As successors and disseminators of such culture, teachers naturally follow this cultural consciousness.

The value thinking of hierarchy. "The so-called value thinking of hierarchy is top and bottom way. It gives higher value (status and prestige) to whoever is on the top, not those at the bottom. Under such way of thinking, different groups are given different stratum" (Han \& Zhang, 2005, p. 195). This value thinking of hierarachy unconsciously shapes the educational pattern of teachers highly above students who are always at the bottom. According to Buber (1966), "me-it" relationship is not a true one at all. The true relationship happens between the two and mutually two-way relationship. This pattern of teacher-student relationship is alienated from "me-you" to "me-it" one-way relationship: Students become the educating and processing objects. They are passive objects, and teachers possess undoubtedly authority.

The ruling logic. "The so-called ruling logic is make-a-point structure. Such structure makes subdued status be proved as rational and justified. The ruling logic is the most essential characteristic" (Du, 2010, 
p. 277). In this logic frame, different groups and their characteristics not only have social stratum and also oppressive. It contains such logic: To A and B, if A is superior to B, then B is subordinate to A. For example, human beings are superior to nature, animal, and other organisms, so it is rational for human beings to oppress nature, animal, and other organisms. Based on this viewpoint, teachers are naturally superior to students because of their training in advance, knowledge, and experiences, together with the mission endowed by the society of educating students. Furthermore, teachers can impose supremacy on students who are in subordinated status.

\section{The Feminist Perspective of TA: Liberation and Freedom}

From the angel of liberated feminist analysis, different groups or individuals have their value and should be respected. They would deserve equal opportunities of development. Such opportunities are not given by others, rather to be fought by the vulnerable groups themselves, the only way leads to liberation and freedom.

\section{The Liberation Perspective of Feminism}

Ever since the beginning of feminism, a variety of theories have coexisted. But one basic premise is that women belong to the oppressed and decimated stratum all over the world. Women are the "secondary gender" as Simone de Beauvoir described. Concerned about the vulnerable groups of women, the realization of men-women equality would be the common pursuit and objects of feminism.

Paulo Freire, who advocated the notion of liberating education, is the most influential educator of the critical theory of education and practice in the 20th century. His main idea is that education is liberation, hope and eventually leads to freedom (Freire, 1990). Having influenced by his liberated education thought, the feminism represented by Freire emphasized that through liberating the oppressed in the process of education, the equality mentality must be awakened in order to realize their own development self-consciously. Their analysis model of women problem is labeled as "liberation analysis model" (Xu \& Zhang 2004). Such sort of models focuses on the combination of gender, nationality, classes, and age, which form a privileged system oppressing vulnerable groups. In the educational field, the "liberation analysis model" is concerned about the macro level of the influence on students' learning by the social structure of oppression and privilege. On the other hand, it pays attention to the rationality of the knowledge teachers passing on over micro teaching, for instance, how the knowledge is selected and who decides what to choose. All these are questions of query and these questions are habitually acquiesced and accepted.

\section{Analysis of TA}

The essence of TA. Regarding the interpretation of authority, Michel Foucault, a famous French philosopher, defined it uniquely:

Authority is not suppressed by the outside control but a practice of predictability. The authority can never be held in someone's hand; neither property nor wealth could be owned. It exists and conducts by the execution of individual and through entity. (Wang, 1999, p. 189)

Foucault emphasized that the authority always manifests in the relations of different influences and such relations exist in a series of events. The authority is formed in such events and the process of interacted events.

In other words, Foucault regarded authority as the interacted relations of different influences, not a quiescent force of suppression and control.

"The different influences" in the classroom are teachers and students. The interacted relations exist 
between teachers and students; such relations shape the TA. Therefore, the essence of TA is the relationship of interacted process between teachers and students. Specifically speaking, it exists among mutual information exchange, influence, and complement between teachers and students. The mutual interaction between teachers and students is a dynamic process of information exchange. Such information consists of knowledge, emotion, attitude, need, interest, value, life experience, and behavior standard. The goal of executing TA is to ensure the information communication go smoothly. Through such extensive interaction of information communicating, "syntony" effect and true join forces will be produced and formed in order to promote the initiative development of students.

The premise of executing TA. During the teaching process, all activities of teaching are based on students. Without the participation of students, the external factor of teaching cannot function at all. Due to the TA of traditional, charisma, legal, and professional, the authority of the teachers obviously outweighs the students who are in comparative weak status. Thus, the unequal relations reveal more about control and restriction. Under control and restriction, the thinking of students is imprisoned and their behaviors are standardized. Students lose their consciousness and capability of executing rights in the classroom. Thus, the key of reasonable implementing TA is how to motivate the initiative of students, not controlling and restraining. Reference to the liberating perspective of feminism, the execution of TA is to reach the ultimate goal of teaching, and in the process of achieving the goal, students' ultimate goal is the subject. Excessive control and restriction only make teaching become one-person show or monodrama. Students could not play a leading role in the process of learning. In order to make students - the disadvantaged - develop well, teachers must liberate students, give them freedom, awaken their subject consciousness, and be aware of their rights. Students have the capability to implement their rights and participate in the teaching process democratically.

\section{The Ways of Implantation of Feminist TA}

The feminist TA focuses on the development of students, cares for the active participation of students in the classroom, and stresses the enhancement of students' subject status through liberation in order to transform the passive study of students.

To implement TA rationally, teachers need to empower students, build a learning community, and create an equal teacher-student relation.

\section{Empowering Students}

The transformation of TA from control-restriction to liberation-freedom is essentially the transformation of authority conception. Nowadays, TA has already transformed from the past authority-held conception to authority-sharing one ( $\mathrm{Hu}, 2009)$. The former regards authority as a predominating relationship in which a certain individual or group possesses capacity to control other individuals or groups. In this authority structure, competition provokes result. Controlling others is a glory. Utilizing hierarchy relationship and external imposed administrative force influences policy-making with frequently used words: controlling, compelling, threatening, manipulating, sanctioning, obeying, and yielding. But latter authority conception incarnates a equal relation in which joint action of different individuals and groups is stressed.

In the process of authority transformation conception, a related terminology "empowerment" has emerged. TA was teachers' patent in the educational field for the past. According to authority-sharing conception, TA should be jointly act under the premise of equality between teachers and students. From the essence of teaching, 
teachers' teaching is to promote students' learning. If students do not cooperate without initiation, teachers' teaching is invalid without any effect on students. Thus, empowering students should be done to let students acquire power and participate in teaching initiatively. By doing so, students can fully voice their ideas and thought in order to make decisions over their own study and accomplish self-development.

One thing must be clarified is that the realization of empowerment does not necessarily mean to deprive of someone's rights and eliminate others' rights and replace it, but to seek the mutual development of cooperation and sharing. At the same time, empowerment is neither obtaining authority externally, nor giving authority passively by someone else. It is the authority originates and develops internally. Authority comes from inside, not from the outside. It is the self-decision of teachers and students with spontaneousness and voluntary. Authority always exists in the process of practical actions of teachers and students. Thus, let students secure strength, not let teachers give part of authority to students. Through liberation of students, students obtain the freedom of thinking and behavior. They would execute the authority of subject and participate in the process of teaching with teachers.

\section{Building a Learning Community}

Professor Sato Manabu at Tokyo University once predicted that schools would be learning communities (Manabu, 2004). Classrooms are the main place for students to learn. Naturally, each school also should be a community of learning. In this learning community, dissimilarity and similarity exist between teachers and students. Such situation would form competition and cooperation among members of the community and mobilize students' enthusiasm, initiative, and creativity in order to safeguard the learning rights of students.

Three things must be done in building a learning community:

1. An atmosphere of security and sense of belonging should be created. In the community, security can let members voluntarily strive for the common goal with other members. Sense of belonging makes members feel their pertaining to this community at any moment and accepted and needed by all members. They have their own values and regard the interests of the community as their interests. Having a sense of security and belonging in the community, members appreciate competition and help each other because they are associated by friendly and mutually dependent emotions;

2. Sharing and interaction should be emphasized. Experience-sharing and interaction are the main ways of community activities. Interactions among members would promote their information communication, share wisdom and experiences collectively, reach consensus over some issues, and impel them to rethink profoundly in order to enhance individuals' capability of perception activity;

3. A common vision should be built. A common vision is the common goal of community members who are willing to strive for it. It is a power of moving and inspiring. It functions to agglomerate, impel, and clarify the goal. As the common vision is established, it can associate members closely and agglomerate powers of all to reach the goal of individuals and the organization. Generally speaking, the common vision is not stipulated by the community authority, but by the interaction of members spontaneously and naturally.

\section{Building a Mutually Caring Teacher-Student Relationship}

According to feminists, the teacher-student relationship is inevitably influenced by the relations of systemized authority and oppression. In traditional teaching, teachers possess privileged authority by the knowledge authority, truthful and theoretical. They ignore the individuality of students, style and discriminate the experiences and feelings of students in an unfavorable situation without the mutual caring between teachers 
and students. In the opinion of feminism, caring is defined as "unselfish caring". It has the aspiration, action, and inclination to enhance the happiness of the cared. It signifies unselfish caring for the cared, not for the self-interest of the care-giver (Noddings, 2003). In such sense, caring has such characteristics: "The relationship between the caring subject and the cared object demands care-giver to be in the position of the object with trouble and fragility to handle the relationship of the cared object" (Manabu, 2004, p. 272). Such caring towards others with concern and sympathy is originated unselfishly and spontaneously from the heart. According to Manabu (2004), education is to "respond to the behavior of the object with fragility, sadness, call, and trouble. It existed in the relation of the cared and a behavior of worrying about the object of concerned" (as cited in Noddings, 2003). Such caring is needed and lacking between teachers and students. The original meaning of caring in education has lost.

Based on this caring, mutual caring should be established between teachers and students in order to create a better accommodating atmosphere between them.

First of all, the "me-it" relation would be replaced by the "me-you" one in order to discard "me-it" relation between teachers and students. "Me-you" relation is an equal one. The equal dialogue and mutual respond can be done between teachers and students. The real responsibility between teachers and students is to respond. Responding to someone is responsible for someone.

In mutual responding, the essential teacher-student relationship happens. Only when such relation takes place, are students not objects of teachers any more, but teachers' students. And teachers can experience the spoken truth of students. In the irrefutable truth, teachers and students' souls collide, resulting in a true concern for reciprocity. The mutual responding between teachers and students is the real mutual caring ( $\mathrm{Du}, 2010)$.

Secondly, circumstances of the opposite side should be understood. Looking at the problem from the opposite perspective, not in self stance with self standards, but in the side of the opposite, can help understand the behavior and idea of the other side. Under such premise, teacher-student interactions can unfold and invoke deep caring of both sides.

\section{Conclusion}

From the feminist perspective, unequal power between teachers and students caused by students' sense of equality has not been awakened.

Teachers and students sharing power, liberation, and freedom is the primary condition to achieve the feminist TA. Teachers can use the following ways to achieve it: to empower students, to build a learning community, and to create a caring relationship between teachers and students .

\section{References}

Buber, M. (1966). Between man and man. New York, N.Y.: The Macmilan Company.

Du, E. M. (2010). The construction of the education world harmony under feminism perspective (p. 280). Chengdu: Sichuan University Press.

Freire, P. (1990). Pedagogy of the oppressed (p. 23). Harmondsworth: Penguin.

Giroux, H. A. (1986). Authority, intellectuals, and the politics of practical learning. Teachers College Record, 88(1), 22-40.

Han, H., \& Zhang, J. (2005). Introduction to women's studies (p. 195). Beijing: Education Science Press.

Hu, S. (2009). Upgrade from the control of power to individual ability-On American teacher empowerment movement "view of power" changes and implications for teachers' professional development. Contemporary Educational Sciences, 11, 31-34.

Hurn, C. (1985). Changes in authority relationships in schools: 1960-1980. Research in Sociology of Education and Socialization, $5,31-57$. 
Lather, P. (1991). Getting smart: Feminist research and pedagogy with/in postmodern. New York, N.Y.: Peter Lang Publishing, Inc..

Li, Q. (2008). Research on teacher power in basic education (Unpublished M.Ed. thesis, Northeast Normal University).

Liu, W. (2010). Effects of classroom teaching authority of their teaching methods. Education Exploration, 8, 70-71.

Manabu, S. (2004). Pleasure of learning: Toward dialogic practice (p. 272). (Q. Q. Zhong, Trans.). Beijing: Education Science Press.

Metz, M. H. (1978). Classrooms and corridors: The crisis of authority in desegregated secondary schools (pp. 45-52). Berkeley: University of California Press.

Noddings, N. (2003). Learned concerning: The other mode of education (pp. 23-39; p. 191). (T. L. Yu, Trans.). Beijing: Education Science Press.

Wang, Y. (1984). Suggestions for teachers' status. Foreign Education Information, 4, 1-5.

Wang, Z. R. (1999). Foucault (p. 189). Changsha: Hunan Education Press.

Wu, W., \& Li, S. (2011). Teacher understanding authority in classroom: A review of sociology of education and ideologies in USA. Comparative Education Research, 254(3), 80-85.

Xu, H., \& Zhang, G. J. (2004). A study of the fanatical models of feminist education theory. Studies in Foreign Education, 168(6), $18-22$. 